\title{
VARIA
}

\section{UNA ALEGORÍA DEL VERANO DE BARTOLOMÉ ESTEBAN MURILLO}

Antiguas referencias documentales contemporáneas a Murillo nos informan que este artista realizó alegorías de las cuatro estaciones, de las cuales escasas noticias posteriores han sido suministradas ${ }^{1}$. Dichas referencias son claramente explícitas pero, a juzgar por la obra actualmente conocida de este artista, no se habían conservado. Don Diego Angulo, en su monumental catálogo de la obra de Murillo, menciona la existencia de una representación de la primavera y otra del verano en el inventario del clérigo sevillano don Justino de Neve, realizado en 1685. Con posterioridad señala la aparición en 1848 de una Primavera y un Otoño en la Arcade Gallerie de Londres ${ }^{2}$. Finalmente, también don Diego Angulo ${ }^{3}$ recoge la existencia en la colección de Lord Normanton, en Ringword Sommerley, de un Hombre con frutos de la cual intuye que se trata de una representación del verano. Esta pintura la conocía a través de una deficiente reproducción ${ }^{4} \mathrm{y}$ al no poderla juzgar debidamente consideró, con su habitual prudencia, no incluirla dentro del catálogo de obras seguras, sino que la situó en el apartado de pinturas discutibles, sin llegar a reproducirla.

Esta pintura parece ser con bastante certeza la que recientemente ha pasado por el comercio de arte londinense procedente de los herederos de Lord Normanton y que va a ser vendida, o se ha vendido ya, a la National Gallery of Scotland ${ }^{5}$ (Fig. 1).

La Alegoría del verano a la que nos referimos presenta a un joven envuelto en una capa que no llega a cubrir su torso ni sus brazos, presentando una semidesnudez propia de la estación veraniega que alegoriza; en sus manos sostiene una cesta con frutas, espléndidamente pintadas, entre las que se identifican peras, manzanas y ciruelas. En la cabeza lleva un turbante en el que están prendidas dos espigas que ciertamente, como ya intuyó don Diego Angulo, le identifican como una representación del verano. La calidad de la pintura es muy alta y en ella se

\footnotetext{
1 D. Angulo, Murillo, Madrid, 1981, v. II, núms. 427-428. Inventario de las pinturas de Justino de Neve, Sevilla, 1685; ítem dos cuadros iguales el uno de la primavera y el otro del berano con sus molduras doradas de Morillo que tienen de largo dos varas menos cuarto, ochenta reales cada uno. Cfr. igualmente D. Kinkead, «Artistes inventoires in Sevilla, 1650 1659», Boletín de la Academia de Bellas Artes de Santa Isabel de Hungría, 1989, p. 47. Tasación de los cuadros de don Justino de Neve, Sevilla, 1685: dos cuadros grandes el uno de la primavera y el otro del verano con sus molduras duradas de Murillo que tienen de largo dos varas menos cuarto, 1.600 reales. Id. «The pictures collection of don Nicolás de Omazur», Burlington Magazine, febrero, 1986, p. 139. Inventario de las pinturas de don Nicolás de Omazur, 1690; ítem cuatro lienzos de los cuatro tiempos del año originales del dicho Murillo.

2 D. Angulo, ob. cit., vol. II, ns. 427 y 428.

${ }^{3}$ D. Angulo, ob. cit., vol. II, n. 2579.

${ }^{4}$ Cfr. Burlington Magazine, enero 1904, p. 24.

5 Agradezco a Dereck Johnes el haberme informado de la reaparición de esta pintura.
} 


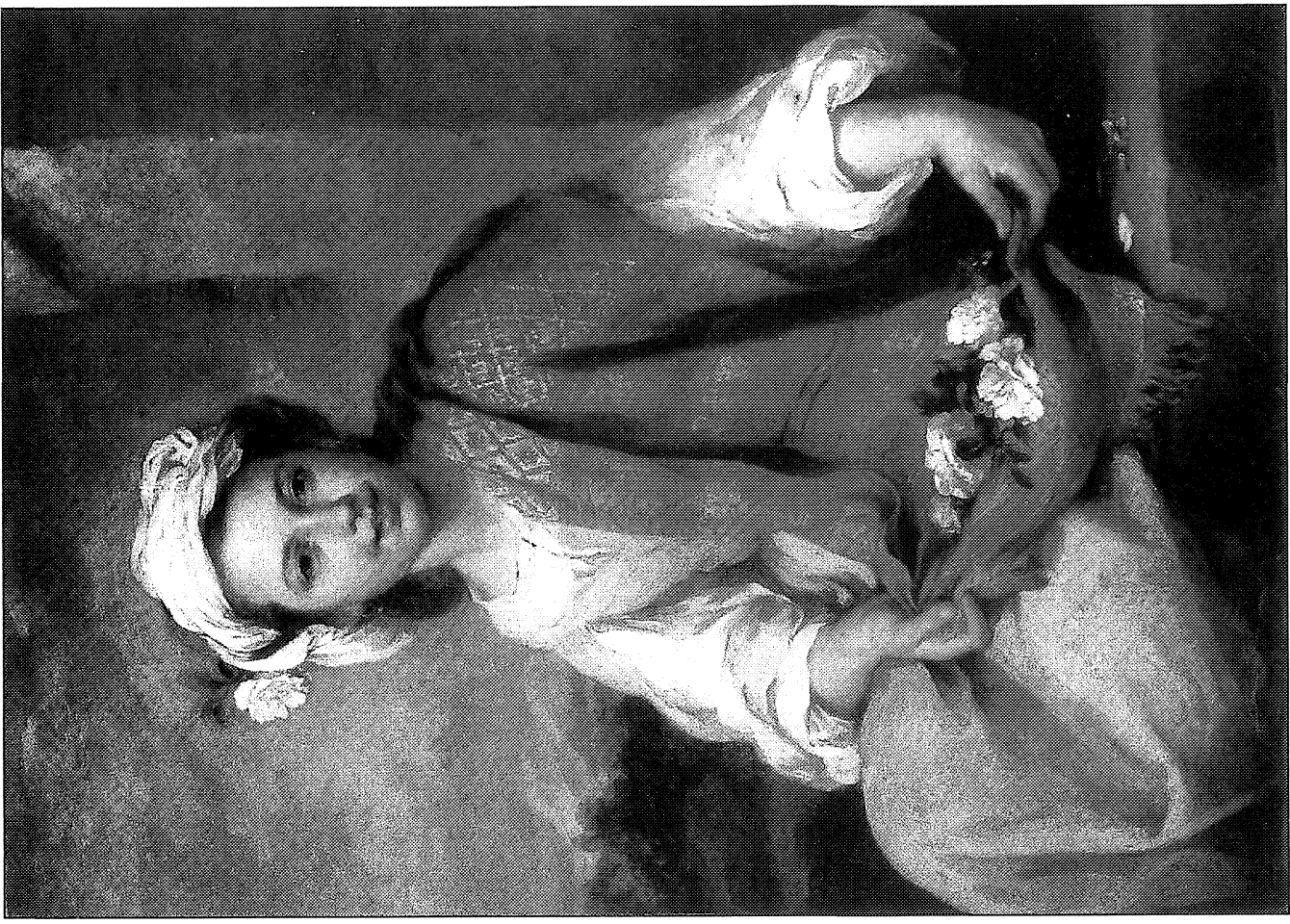

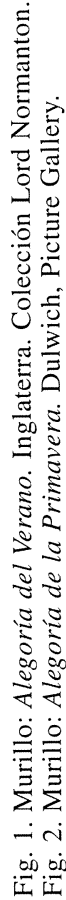

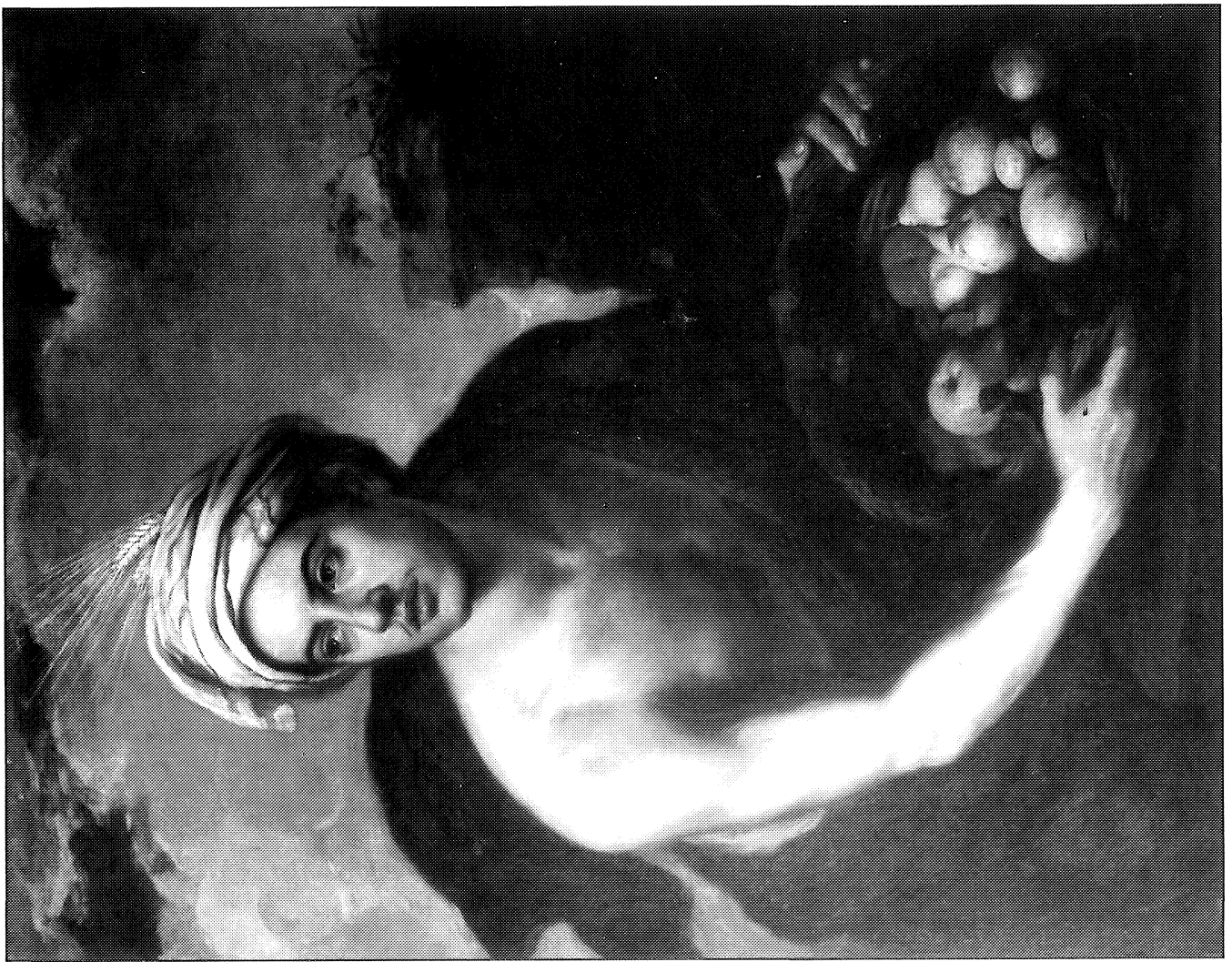


reconoce el estilo de Murillo en todo su esplendor en fechas que pueden oscilar entre 1665 y 1670. El estudio anatómico del joven es extremadamente correcto y al mismo tiempo aparece magníficamente captada la expresión de su rostro, concentrada y serena ${ }^{6}$.

Tiene, además, esta pintura claras referencias de su permanencia en España antes de salir de nuestro país, puesto que tenemos la certeza de que pasó por la colección de Godoy tal y como figura en 1850 en el catálogo de la venta de las pinturas del marqués de Montcalm en París ${ }^{7}$. En dicho catálogo de venta se describe esta pintura de la forma siguiente: Murillo l'Esclave un jeune esclave coiffe d'un turban porte de fruits dans une corbeille. D'une belle couleur et d'une execution pleine d'energie. Il a fait partie de la collection du Prince de la Paix. Aut 1 metre large $80 \mathrm{cem}$. Como puede comprobarse el cuadro es el mismo que aquí recogemos ya que sus medidas son prácticamente exactas.

Una última cuestión se nos ocurre a propósito de esta pintura y es que la Niña con flores, obra de Murillo en la Dulwich Picture Gallerie, aunque no forma pareja con esta Alegoría del Verano, sino que pertenece a otra serie pictórica, es muy posible que sea una Alegoría de la Primavera, tal y como puede observarse, puesto que ambas obras presentan claras similitudes compositivas (Fig. 2). Se trata de una joven figura femenina con un turbante sobre su cabeza en el que está prendida una rosa y que muestra un conjunto de flores en su regazo. Ambas obras están respaldadas por restos arquitectónicos a la derecha y un paisaje, aunque este detalle es casi invisible en la Alegoría del Verano ${ }^{8}$.

ENRIQUE VALDIVIELSO

Departamento de Historia del Arte de la Universidad de Sevilla

\section{UN «DESCENDIMIENTO» DE PABLO VERONÉS Y DOS DE SU HIJO CARLETTO EN EL ESCORIAL}

El Monasterio de El Escorial cuenta con tres «Descendimientos» catalogados por Poleró como obras de Carlo Caliari: dos en los Nuevos Museos (n. ${ }^{\circ} 85$ del cat. Poleró: L. 69,5 × 89; n. ${ }^{\circ} 189$ del cat. Poleró: L. $\left.178 \times 193\right)$ y uno en el Panteón de Infantes (n. ${ }^{\circ} 113$ del cat. Poleró: L. $272 \times 163$ ). Con el presente artículo se va a tratar de demostrar que el más pequeño debe atribuirse a su padre, Pablo Veronés, y de clarificar, en la medida de lo posible, a cuáles de ellos se refieren las menciones antiguas que se han logrado recoger.

Conviene empezar por el más pequeño que, además de ser el de más calidad, figura en

\footnotetext{
${ }^{6}$ Mide $100 \times 76 \mathrm{cms}$. Dimensiones que coinciden casi exactamente con las que don Diego Angulo recogió al referirse al cuadro de Lord Normanton.

${ }^{7}$ Catalogue de la seconde et plus important partie de la Belle Colection de tableaux de M. Le marquise de Montcalm de Montpellier, París, 25 de marzo de 1850. Agradezco enormemente a Isadore Rose-de Viejo el haberme proporcionado esta noticia que procede de su tesis doctoral: Manuel Godoy, patrón de las artes y coleccionista, Madrid, Universidad Complutense, 1983, vol. II, pp. 758-759.

${ }^{8}$ En este sentido, hemos de manifestar que nos cuesta mucho trabajo creer que esta Niña con flores de Dulwich sea un cuadro con contenido erótico tal y como manifestó J. Brown en su artículo: «Murillo, pintor de temas eróticos. Una faceta inadvertida de su obra». Goya, núms. 169-171, julio-diciembre 1982. Ciertamente nos parece impensable admitir que una persona como Murillo, fielmente vinculada a la estricta moral católica imperante en Sevilla en la segunda mitad del siglo XVII, sumamente restrictiva a la hora de aceptar representaciones pictóricas de contenido pecaminoso, pueda haber incurrido en una escena de carácter lascivo.
} 